УДК 621.311 .1

Михайленко Виктор Сергеевич, Пейзель Вилена Марковна, Степанова Анна Александровна

\title{
ПРОГРАММНЫЙ КОМПЛЕКС \\ ДЛЯ РАСЧЕТА МЕХАНИЧЕСКИХ ХАРАКТЕРИСТИК ВОЗДУШНЫХ ЛИНИЙ ЭЛЕКТРОПЕРЕДАЧИ
}

В статье предложено описание программного комплекса, предназначенного для расчета механических характеристик воздуиных линий электропередач (ВJI), и его функциональных возможностей. Комплекс использует структурированную базу данных по всем конструктивным элементам ВЛ, которая может быть легко модифицирована в прочессе эксплуатации. Програмиа выполияет полный комплекс задач механического расчета $B Л$.

В основу расчета положены традицонные методики, применяемые при проектировании механической части ВЛ. При расчете механических параметров ВЛ в программе учтень климатические характеристики трассы и ее особенности. В основу расчета механических характеристик проводов и изоляторов В Л положсны метод допустимых напряжсеий (для ВЛI) и метод разрушаюичих нагрузок (для изоляторов).

Ключевые слова: линия электропередачи; удельная механическая нагрузка; механическое напряжение провода; стрела провеса.

\section{Viktor Mikhaylenko, Vilena Peyzel, Anna Stepanova \\ PROGRAM COMPLEX FOR THE CALCULATION OF MECHANICAL CHARACTERISTICS OF AIR ELECTRICAL TRANSMISSION LINES}

The article proposes a description of the software package designed to calculate the mechanical characteristics of overhead power lines $(O H L)$, and its functionality. The complex uses a structured database of all the structural elements of the OHL, which can be easily modified during operation. The program performs the full range of tasks of mechanical calculation of overhead lines

The calculation is based on traditional techniques used in the design of the mechanical part of the $O H L$. When calculating the mechanical parameters of the OHL, the program takes into account the climatic characteristics of the route and its features. The calculation of the mechanical characteristics of wires and insulators of overhead lines is based on the method of permissible stresses (for overhead lines) and the method of destructive loads (for insulators).

Key words: power line; specific mechanical load; the mechanical stress of the wire; sag.

Bведениe / Introduction. В «Правилах устройства электроустановок» (ПУЭ) воздушная линия определяется как устройство для передачи электрической энергии по проводам, расположенным на открытом воздухе и прикреплённым при помощи изоляторов и арматуры к опорам или кронштейнам инженерных сооружений. Указанные конструктивные элементы ВЛ подвергаются в процессе эксплуатации воздействию значительных механических нагрузок, в особенности при сочетаниях неблагоприятных климатических условий, что является причиной тяжелых аварий, последствиями которых могут быть длительные перерывы электроснабжения потребителей. Поэтому как при проектировании, так и при эксплуатации ВЛ обязательным требованием к элементам ее конструкции является обеспечение надежной работы по условиям механической прочности. Подходы к разработке единой стратегии, нормативно-справочные материалы, а также алгоритмы решения задач по расчету механических характеристик линий электропередачи представлены в научной учебной литературе: [2-5], справочной [6, 7], и ряде научных публикаций [8-10]. 
Mameриалы и методы/Materials and methods. Комплекс задач, включающий в себя определение механических характеристик проводов воздушной линии в нормальных и аварийных режимах традиционно носит название «Механический расчет ВЛ». Программная реализация комплекса задач такого рода предполагает использование большого количества справочных материалов различного характера (климатические характеристики районов прохождения трассы ВЛ, регламентированные требования к элементам конструкции, вертикальные и горизонтальные габариты ВЛ, физико-механические показатели проводов и тросов, изоляции ВЛ и т. д.), что вызывает необходимость использования базы данных, которая бы могла быть структурирована по виду и характеру справочных данных и легко модернизировалась бы в процессе эксплуатации.

В настоящее время при проектировании механической части ВЛ в России активно используются промышленные программные комплексы. К их числу в первую очередь можно отнести:

1) Программный комплекс Model Studio CS, разработанный группой компаний Csoft в 2015 году и предназначенный для проектирования ВЛ всех классов напряжения (от 0,4 до $750 \mathrm{kB}$ ). Model Studio CS ЛЭП представляет собой одну программу, не разделенную модулями или промежуточными файлами и работающую с единой целостной моделью проекта непосредственно в среде AutoCAD. Несомненными достоинствами программы являются быстрые алгоритмы, сверхскоростные возможности расчета и оформления. Программа использована компаниями ООО «Инженерный центр энергетики Башкортостана», ОАО «Тюменьэнерго», ОАО «Дальэнергосетьпроект» [11];

2) Программный комплекс LineMech, разработанный компанией Line Cross в 2008 году, позволяющий выполнять расчёты нагрузок, критических пролетов, тяжений, напряжений и стрел провеса проводов, тросов, самонесущих кабелей (в том числе волоконно-оптических линий связи, ВОЛС), линий электропередачи любого напряжения в расчётных (ПУЭ) и монтажных режимах [12];

3) Программный комплекс EnergyCS Line, разработчиком которого является группа компаний Csoft, предназначен для автоматизации проектирования механической части воздушных линий электропередач (ВЛ), волоконно-оптических линий связи (ВОЛС), подвешиваемых на опорах ВЛ, а также гибких ошиновок открытых распределительных устройств (ОРУ) электрических станций и подстанций [13].

Комплекс применен ОАО «ВНИПИгаздобыча» при проектировании линии электропередач на одном из газовых месторождений в Ямало-Ненецком АО.

Pезультаты и обсуждение / Results and discussion. В статье предлагается разработанный на кафедре АЭСиЭ инженерного института СКФУ программный комплекс расчета механической части ВЛ, реализующий проектные методики на основании единой информационной базы и предоставляющий возможность выбора варианта конструкции ВЛ (марки провода, типа опоры, линейной изоляции) и автоматизированного выполнения расчетов проводов и тросов в нормальных режимах.

В настоящее время комплекс используется при изучении курса «Сооружение ЛЭП» студентами направления 13.03.02 Электроэнергетика и электротехника и курса «Проектирование электропередач〉 магистрами по направлению подготовки 13.04.02 Электроэнергетика и электротехника направленности (профиля) «Мониторинг и управление режимами электрических сетей на базе интеллектуальных информационно-измерительных систем и технологий».

Основные функциональные возможности программы:

- $\quad$ выбор проводов, опор, изоляторов из информационной базы. После ввода данных программа автоматически предлагает марки проводов, опор и изоляторов, в соответствии с требованиями, продиктованными климатическими условиями и номинальным напряжением линии;

- $\quad$ расчет высоты приведенного центра масс трехфазной системы проводов, необходимый для определения поправочных коэффициентов на толщину стенки гололеда и скоростной напор ветра; 
- расчет поправочных коэффициентов и определение расчетных значений толщины стенки гололеда и скоростного напора ветра (рис. 1);

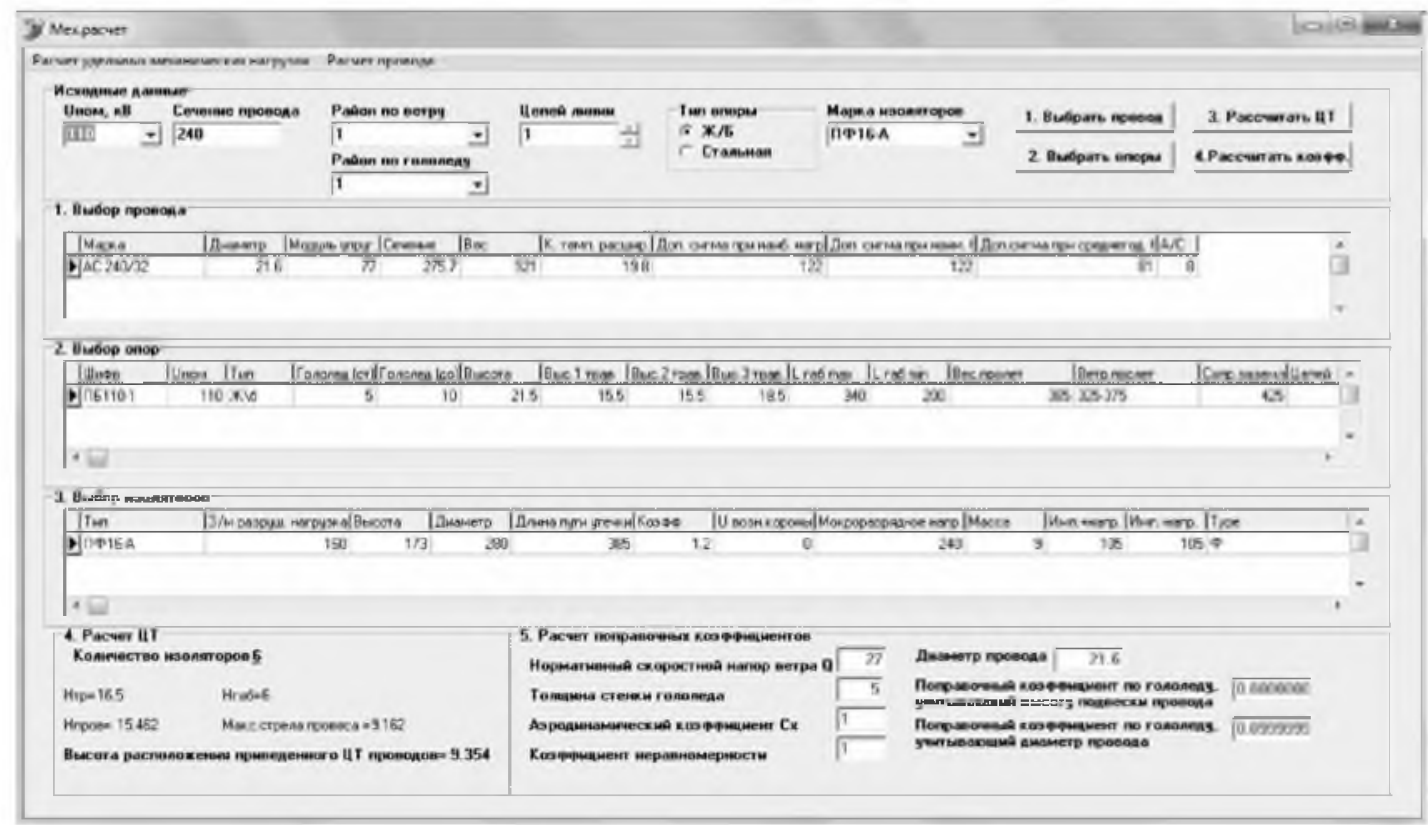

Рис. 1. Главное окно программы

- $\quad$ расчет удельных механических нагрузок (рис. 2);

- расчет значений критических пролетов для выбора исходного режима;

- определение исходного режима путем анализа соотношений трех критических пролетов и габаритного пролета ВЛ;

- систематический расчет проводов, в ходе которого определяются напряжения и стрелы провеса провода для всех расчетных режимов (рис. 3 ).

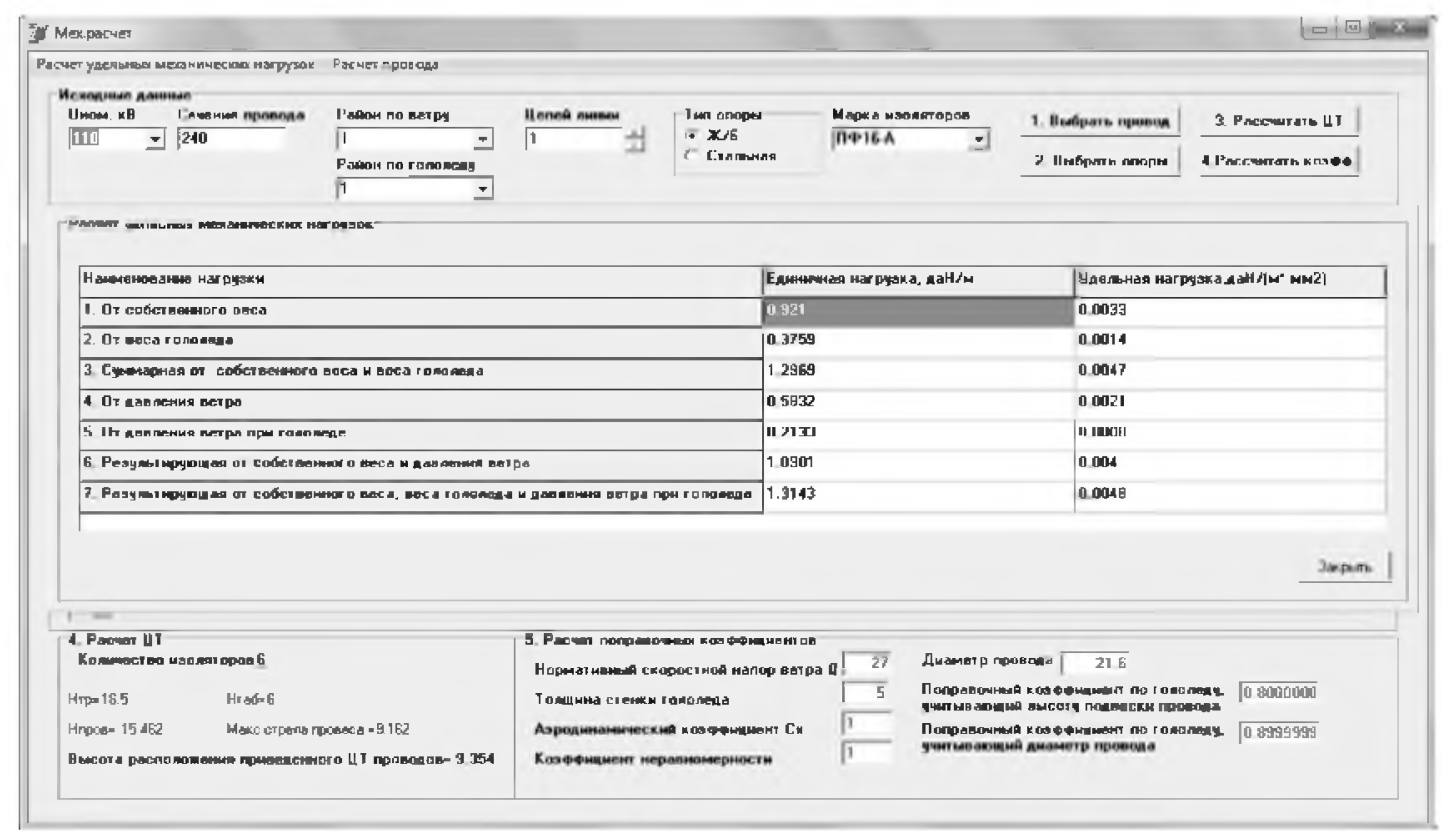

Рис. 2. Расчет удельных механических нагрузок 


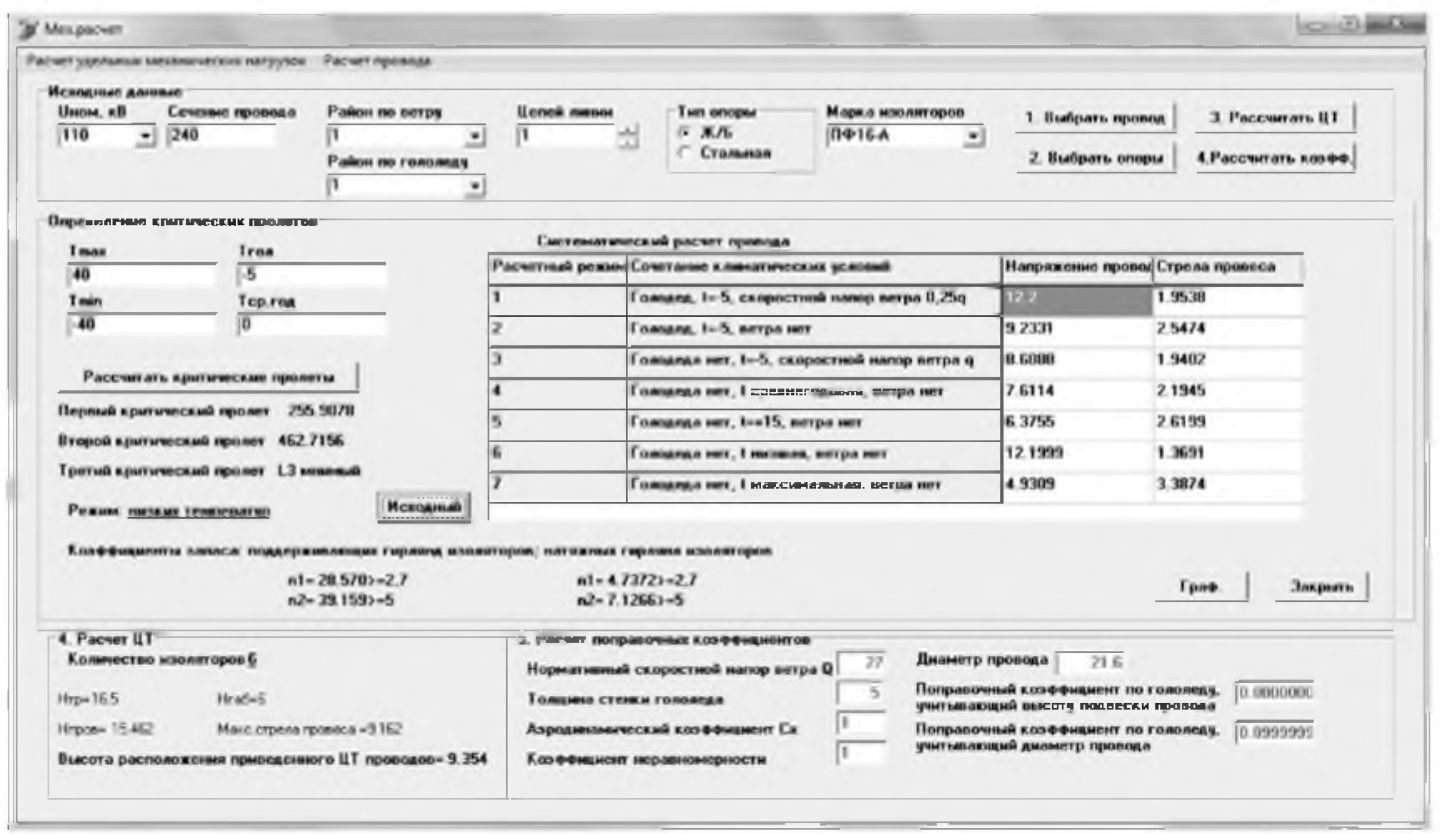

Рис. 3. Систематический расчет проводов

Заключение / Conclusion. Комплекс находится в стадии разработки и будет дополнен модулями, реализующими расчет редуцированного напряжения в проводе и стрелы провеса в аварийных режимах, и расчет показателя грозоупорности ВЛ (и ее участков) при грозовых перенапряжениях. Комплекс может быть эффективно применен для осуществления мониторинга механических характеристик элементов ВЛ в процессе ее эксплуатации, а также для исследования влияния тех или иных мероприятий на улучшение ее эксплуатационных характеристик.

\section{ЛИТЕРАТУРА И ИНТЕРНЕТ-РЕСУРСЫ}

1. ГОСТ 19.701-90 Схемы алгоритмов, программ, данных и систем

2. Крюков К. П., Новгородцев Б. П. Конструкция и механический расчет ЛЭП. Л.: Изд-во «Энергия», $1979.312 \mathrm{c}$.

3. Электрические системы. Электрические сети: учебник для электроэнергетических спец. вузов / В. А. Веников, А. А. Глазунов, Л. А. Жуков и др.: под ред. В. А. Веникова, В. А.Строева. 2-е изд., перераб. и доп. М.: Высш. шк., 1998. 511 с.

4. Зеличенко А. С., Смирнов Б. И. Проектирование механической части воздушных линий сверхвысокого напряжения. М.: Энергоиздат, $1981.336 \mathrm{c}$.

5. Костин В. Н. Системы электроснабжения. Конструкции и механический расчет: учебное пособие. СПб.: СЗТУ. $93 \mathrm{c}$.

6. Справочник по проектированию линий электропередачи / М. Б. Вяземский, В. Х. Ишкин, К. П. Крюков и др. / под ред. М. А. Реута и С. С. Рокотяна. 2-е изд., перераб. и доп. М.: Энергия, 1980. 296 с.

7. Макаров Е. Ф. Справочник по электрическим сетям 0,4-35 и 110-1150 кВ / под ред. И. Т. Горюнова, А. А. Любимова. М.: Папирус Про. 2003. 640 с.

8. Петров В. С., Дубровская Т. И. Механический расчет проводов и тросов воздушных линий как основа расчета надежности конструкций // Науковедение: интернет-журнал. 2015. Т. 7. № 6. С. 1-13.

9. Методические указания по расчету климатических нагрузок в соответствии с ПУ.Э-7 и построению карт климатического районирования. М., 2010. $101 \mathrm{c}$.

10. Луговой В. А., Тимашова Л. В., Черешнюк С. В. Климатические нагрузки на ВЛ. Проблемы механики ВЛ, климатические условия, нагрузки и воздействия, колебания проводов и методы их ограничения. М.: ЭНАС, 2004. 124 с. 
11. Воробьев С. Прирученная автоматизация или Как выполнить проект в Model Studio CS ЛЭП // CADmaster. 2010. № 2 (52). (апрель - июнь). URL: https://www.mscad.ru/uses/articles/cm_52_17.html (дата обращения: 23.04.2019).

12. URL: http://www.linecross.ru/manual/linemech.htm (дата обращения: 19.04.2019).

13. URL: http://www.csoft.ru/catalog/soft/energycs-line/energycs-line-3.html (дата обращения: 25.04.2019).

\section{REFERENCES AND INTERNET RESOURCES}

1. GOST 19.701-90 Shemy algoritmov, programm, dannyh i sistem (Schemes of algorithms, programs, data and systems).

2. Krjukov K. P., Novgorodcev B. P. Konstrukcija i mehanicheskij raschet LJeP (Construction and mechanical calculation of power lines). Lю: Izd-vo «Jenergija», 1979. $312 \mathrm{~s}$.

3. Jelektricheskie sistemy. Jelektricheskie seti: Uchebnik dlja jelektrojenergeticheskih spec. Vuzov (Electrical systems. Electrical Networks: A textbook for electric power specials. Universities) / V. A. Venikov, A. A. Glazunov, L. . Zhukov i dr:: pod red. V. A. Venikova,V. A. Stroeva. 2-e izd., pererab. i dop. M.: Vyssh. shk., 1998. 511 s.

4. Zelichenko A. S., Smirnov B. I. Proektirovanie mehanicheskoj chasti vozdushnyh linij sverhvysokogo naprjazhenija (Designing the mechanical part of super high voltage overhead lines). M.: Jenergoizdat, $1981.336 \mathrm{~s}$.

5. Kostin V. N. Sistemy jelektrosnabzhenija. Konstrukcii i mehanicheskij raschet (Power supply systems. Constructions and mechanical calculational): uchebnoe posobie. SPb.: SZTU. $93 \mathrm{~s}$.

6. Spravochnik po proektirovaniju linij jelektroperedachi (Guidelines for the design of power lines) / M. B. Vjazemskij, V. H. Ishkin, K. P. Krjukov i dr;; pod red. M. A. Reuta i S. S. Rokotjana. 2-e izd., pererab. i dop. M.: Jenergija, 1980. $296 \mathrm{~s}$.

7. Makarov E. F. Spravochnik po jelektricheskim setjam 0,4-35 i 110-1150 kV (Handbook of 0.4-35 and 110$1150 \mathrm{kV}$ electrical networks) / pod redakciej I. T. Gorjunova, A. A. Ljubimova. M.: Papirus Pro. 2003. $640 \mathrm{~s}$.

8. Petrov V. S., Dubrovskaja T. I. Mehanicheskij raschet provodov i trosov vozdushnyh linij kak osnova rascheta nadezhnosti konstrukcij (Mechanical calculation of wires and cables of overhead lines as the basis for calculating the reliability of structures) // Naukovedenie: Internet-zhurnal. 2015. T. 7. No 6. S. 1-13.

9. Metodicheskie ukazanija po raschetu klimaticheskih nagruzok na VL i postroeniju regional'nyh kart $s$ povtorjaemost'ju $1 \mathrm{raz}$ v 25 let. (Guidelines for the calculation of climatic loads on high-voltage lines and the construction of regional maps with a frequency of 1 every 25 years). M., 1990. $101 \mathrm{~s}$.

10. Lugovoj V.A., Timashova L. V., Chereshnjuk S. V. Klimaticheskie nagruzki na VL. Problemy mehaniki VL, klimaticheskie uslovija, nagruzki i vozdejstvija, kolebanija provodov i metody ih ogranichenija (Climatic loads on OHL. Problems of overhead transmission mechanics, climatic conditions, loads and impacts, wire vibrations and methods for their limitation). M.: JeNAS, 2004. $124 \mathrm{~s}$.

11. Vorob'ev S. Priruchennaja avtomatizacija ili Kak vypolnit' proekt v Model Studio CS LJeP (Tamed Automation or How to run a project in Power Line Model Studio CS )// CADmaster. 2010. № 2 (52) (aprel' ijun'). URL: https://www.mscad.ru/uses/articles/cm_52_17.html (data obrashhenija: 23.04.2019).

12. URL: http://www.linecross.ru/manual/linemech.htm (data obrashhenija: 19.04.2019).

13. URL: http://www.csoft.ru/catalog/soft/energycs-line/energycs-line-3.html (data obrashhenija: 25.04.2019).

\section{СВЕДЕНИЯ ОБ АВТОРАХ}

Михайленко Виктор Сергеевич, студент 3 курса бакалавриата кафедры автоматизированных электроэнергетических систем и электроснабжения инженерного института СКФУ. E-mail: imivise (a) gmail.com

Пейзель Вилена Марковна, канд. техн. наук, доцент кафедры автоматизированных электроэнергетических систем и электроснабжения инженерного института СКФУ. E-mail: pvm1955@inbox.ru

Степанова Анна Александровна, канд. техн. наук, доцент кафедры автоматизированных электроэнергетических систем и электроснабжения инженерного института СКФУ. E-mail: annaastepanova@gmail.com

\section{INFORMATION ABOUT AUTHORS}

Viktor Mikhaylenko, 3rd year undergraduate student of the department of automated electric power systems and power supply of the engineering institute of NCFU. E-mail: imivise@gmail.com

Vilena Peyzel, Candidate of Technical Sciences, Senior lecturer of the Chair of Automatic Electrical Power Systems and Electric Power Supply, Engineering Institute, NCFU. E-mail: pvm1955@inbox.ru

Anna Stepanova, Candidate of Technical Sciences, Senior lecturer of the Chair of Automatic Electrical Power Systems and Electric Power Supply, Engineering Institute, NCFU. E-mail: annaastepanova@gmail.com 